$\therefore$ LA-UR-

Approved for public release; distribution is unlimited.
DEFLAGRATION TO DETONATION EXPERIMENTS IN GRANULAR HMX

$$
\text { CONF-97/0108-- }
$$

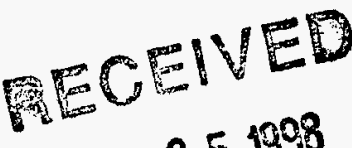

MAR 251998

Q. 5 Tा
Author(s):

Submitted to:
Nathan J. Burnside Steven F. Son Blaine W Asay
1997 JANNAF CS/PSHS/APS Joint Meeting Pratt \& Whitney and Palm Beach Gardens Hotel,

West Palm Beach, Florida

October 27-31, 1997

Los Alamos National Laboratory, an affirmative action/equal opportunity employer, is operated by the University of California for the U.S. Department of Energy under contract W-7405-ENG-36. By acceptance of this article, the publisher recognizes that the U.S. Govemment retains a nonexclusive, royalty-free license to publish or reproduce the published form of this contribution, or to allow others to do so, for U.S. Govemment purposes. Los Alamos National Laboratory requests that the publisher identify this article as work performed under the auspices of the U.S. Department of Energy. The Los Alamos National Laboratory strongly supports academic freedom and a researcher's right to publish; as an institution, however, the Laboratory does not endorse the viewpoint 


\section{DISCLAIMER}

This report was prepared as an account of work sponsored by an agency of the United States Government. Neither the United States Government nor any agency thereof, nor any of their employees, makes any warranty, express or implied, or assumes any legal liability or responsibility for the accuracy, completeness, or usefulness of any information, apparatus, product, or process disclosed, or represents that its use would not infringe privately owned rights. Reference berein to any specific commercial product, process, or service by trade name, trademark, manufacturer, or otherwise does not necessarily constitute or imply its endorsement, recommendation, or favoring by the United States Government or any agency thereof. The views and opinions of authors expressed herein do not necessarily state or reflect those of the United States Government or.any agency thereof. 


\title{
DEFLAGRATION TO DETONATION EXPERIMENTS IN GRANULAR HMX ${ }^{1}$
}

\author{
N. J. Burnside, S. F. Son, B. W Asay, and P. M. Dickson \\ Los Alamos National Laboratory \\ Los Alamos, NM 87545
}

\begin{abstract}
In this paper we report on continuing work involving a series of deflagration-to-detonation transition (DDT) experiments in which we study the piston-initiated DDT of heavily confined granular cyclotetramethylenetetranitramine (HMX). These experiments were designed to be useful in model development and evaluation. A main focus of these experiments is the effect of density on the DDT event. Particle size distribution and morphology are carefully characterized. In this paper we present recent surface area analysis. Earlier studies demonstrated extensive fracturing and agglomeration in samples at densities as low as 75\% TMD as evidenced by dramatic decreases in particle size distribution due to mild stimuls. This is qualitatively confirmed with SEM images and quantitatively studied with gas absorption surface area analysis. Also, in this paper we present initial results using a microwave interferometer technique. Dynamic calibration of the technique was performed, a $35 \mathrm{Ghz}$ signal is used to increase resolution, and the system has been designed to be inexpensive for repeated experiments. The distance to where deformation of the inner wall begins for various densities is reported. This result is compared with the microwave interferometer measurements.
\end{abstract}

\section{INTRODUCTION}

DDT tubes, initiated thermally or by low-speed impact of a piston, have been used for years to study the DDT process in granular explosives (Griffiths and Groocock 1960; Korotkov, Sulimov et al. 1969; Bernecker, Sandusky et al. 1981; Samirant 1981; Bernecker, Sandusky et al. 1985; Samirant 1985; Bernecker 1986; Bernecker 1989; Samirant 1989; Luebcke, Dickson et al. 1995; Luebcke, Dickson et al. 1996). Much has been learned concerning the DDT process in granular materials from these experiments, however significant gaps remain between the desired data base and available data for model development and evaluation.

The run-to-detonation can be a strong function of density (or porosity), and is therefore of significant interest. The effect of density on run-to-detonation for granular HMX was examined in the early experimental study of Griffiths and Groocock (1960). For several reasons, however, these data are of only qualitative value. Other data also have been reported for run-to-detonation as a function of density (e.g., Korotkov, Sulimov et al. 1969; Luebcke, Dickson et al. 1995; Luebcke, Dickson et al. 1996), but thermal ignition was used and granular HMX was not considered. Interestingly, some recently reported data do not show a U-shaped density dependence in granular CP (Luebcke, Dickson et al. 1996).

Because of the complex nature of the ignition, and early conductive and convective burning in thermally ignited DDT tubes, piston-driven experiments have been used here at Los Alamos National Laboratory (LANL) (McAfee, Asay et al. 1991) and elsewhere (Sandusky 1983). In the LANL experiments a combustion-driven piston ignites particles in the granular bed by compaction, which starts all the processes in a single plane at one end of the tube. These experiments were heavily diagnosed using a variety of pins, transducers, and $\mathrm{x}$-radiography and provide a detailed picture of piston-initiated DDT for a narrow set of conditions (e.g., only a single density was considered). Although these results give a detailed picture of the DDT event for the conditions considered, little information is obtained concerning the effect of several parameters that are known to be important, including the effect of density. This makes the development and evaluation of improved models difficult. This effort is an attempt to address this issue.

In this paper we present further characterization of the granular HMX used, initial calibration and use of a microwave interferometer technique, and further DDT experiments.

\section{EXPERIMENTAL}

The apparatus used in the DDT tube experiments is shown schematically in Fig. 1. The DDT tube used was a thick walled $77.6 \mathrm{~mm}$ o.d. stainless steel 304 tube with a 96.5 $\mathrm{mm}$ length and $6.4 \mathrm{~mm}$ i.d. The 143:1 inner to outer cross sectional area provided enough inertial confinement to contain the DDT event radially. The piston was loaded into the bottom end of the tube and set flush with the bottom surface. HMX was incrementally loaded directly into the tube in $3 \mathrm{~mm}$ lengths, and a lexan plug was set in the end to temporarily confine the bed.

The ignitor block was made of vascomax 250 maraging steel. A PYROFUSE(B) was set into the bottom of the chamber with a thin mixture of titanium and boron, a gasless pyrotechnic, covering the bridge wire. A load of loose HMX in the burn chamber was ignited by the burning titanium and boron and the burning HMX powder raised pressures enough to drive the piston into the bed of HMX leading to initiation. A pressure transducer (PCB 109A02) was mounted into the side of the burn chamber, and in the first two tests, side closure pins were positioned at four locations near the bottom of the tube. The mating lip between the ignitor block and main tube was sealed with a thin copper washer to prevent

${ }^{1}$ This work sponsored by the U. S. Department of Energy under contract number W-7405-ENG-36. Approved for public release; distribution is unlimited. Presented at the 1997 JANNAF PSHS Meeting, Palm Beach, Florida, Oct. 2731, 1997. Authors'email: burnside@byu.edu, steve@son.org, bwa@lanl.gov. Authors' URLs: http://www.et.byu.edu/ burnsidn, http://steve.son.org, http://sonhp.lanl.gov/asay/blaine.html 
venting, and the entire assembly was held together with four one inch thread bolts. A small hole in the upper confinement plate allowed visual inspection of tube for residual explosive

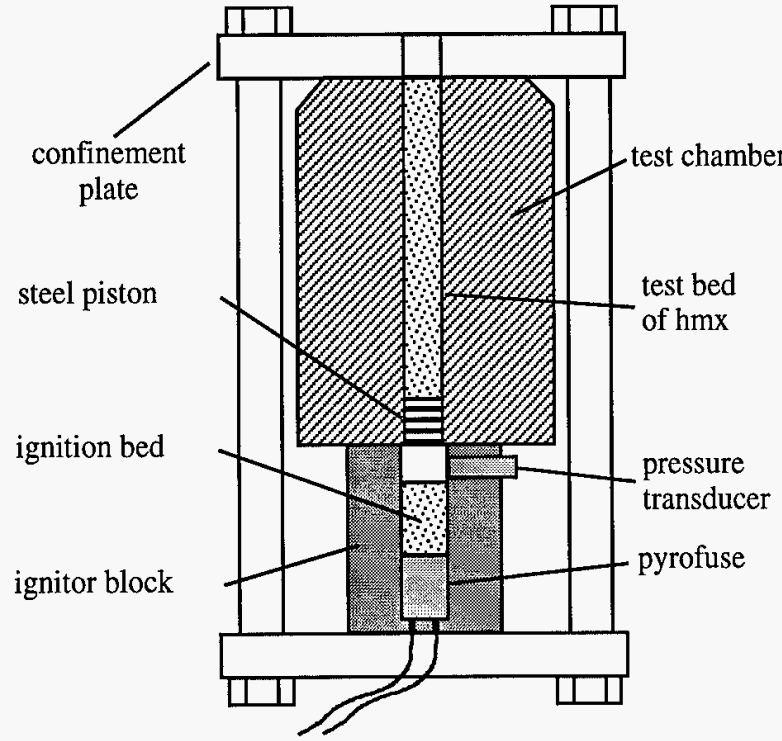

Fig. 1 Diagram of DDT tube experiment.

before disassembly. On the four later shots, a capped pin was set in the top of the tube as an indicator of when the detonation had reached the end of the tube. All pressure data were collected using a pair of LeCroy $9400 \mathrm{~A}$ Dual channel oscilloscopes. The PYROFUSE® was ignited by a low voltage CDU, and the capped pin data were collected by a time interval meter.

\{add background here??\} A composed $35 \mathrm{GHz}$ Microwave interferomter was used to determine detonation speed and position. In various experiments. The interferometer aparatus consists of two ocillators $(8 \mathrm{Ghz}$ and $27 \mathrm{Ghz}$ ), mixed to get an overall frequency of $35 \mathrm{GHz}$. The output signal is guided to the experiment through a waveguide (rolled teflon). The top plate of the experiment has been modfied to have a conical hole to minimize reflections in the transition from the waveguide to the circular hole of the DDT tube. The only part of the microwave system not reusable is the teflon waveguide which minimizes shot-to-shot costs. A critical aspect of this diagnostic is the measurement of the dielectric constant for the materials used. This was measured

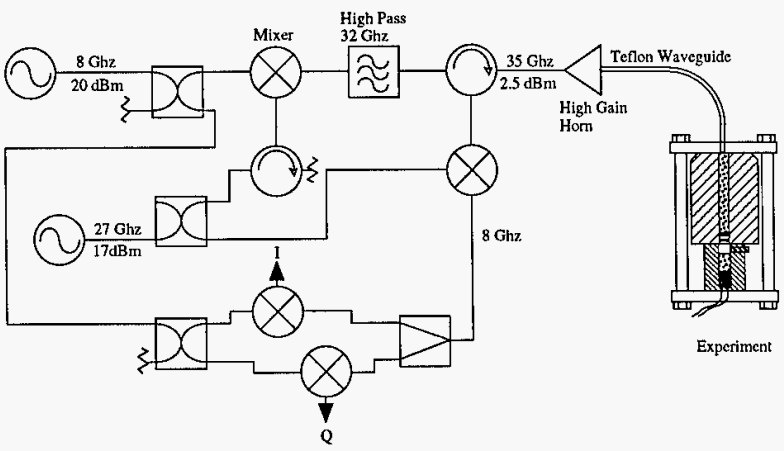

Fig. 2 Diagram of microwave interferometer. dynamically using a detonation in various densities. This is presented in a latter section.

To examine the effect of pressing, eight samples of Class A HMX were prepared starting with poured density, about 64\% TMD, and increasing by increments of 5\% TMD from $65 \%$ TMD to $95 \%$ TMD (100\% TMD=1.903 $\mathrm{g} / \mathrm{cc})$. To reduce density gradients, the samples were pressed at $3 \mathrm{~mm}$ increments in a 0.25 in diameter die, and samples were removed from the die after every three increments. Samples that formed pellets (above 80\% TMD) due to high density pressing were carefully deconsolidated to powder by hand. The pressures needed to deconsolidate the pellets were very small compared to pressures experienced in the pressing procedure, and were therefore considered to have little effect on particle characteristics. Butler et al. (4) made this assumption for low density sugar samples, but did not test higher density samples (>72.2\% TMD).

Particle size analysis was done using a Coulter LS 230 Particle size analyzer which uses light scattering of particles to measure size distributions Samples were taken from solutions of about $0.1 \mathrm{~g} \mathrm{HMX}$ in a bath of $10 \mathrm{ml}$ of distilled water. Because of quick settling of the larger particles, a magnetic stir bar was used to obtain samples representative of the entire distribution. Samples of approximately $1 \mathrm{ml}$ were quickly transported from the solution to the particle analyzer using a dropper.

Two sets of experiments were performed with the particle size analyzer. In the first set, the 8 samples of HMX which had been pressed then deconsolidated were analyzed for particle size distributions. In the second set of experiments, HMX from the same batch of samples was first put into a low power ultrasonic cleaning bath, $1.8 \mathrm{w} / \mathrm{in}^{2}$ at $48 \mathrm{kHz},(7)$ for one minute, then introduced into the analyzer. A magnetic stir bar was once again used to ensure uniformity in the samples.

Surface area analysis was performed on the samples using a Quantachrome AUTOSORB-1 Surface area analyzer, which measures quantities of gas adsorbed and desorbed on a solid surface. This instrument performs a multipoint Brunauer-Emmett-Teller (BET) analysis using nitrogen as the adsorbate.

Finally, structure of the HMX was qualitatively analyzed using a Scanning Electron Microscope (SEM). Samples were observed and photographed extensively. These images are available at: http://sonhp.lanl.gov/sem_jpg.

\section{PARTICLE CHARACTERIZATION}

Works by Elban et al. (1) and Coyne et al. (2) have focused on the compaction process of very coarse $(-900 \mu \mathrm{m})$ granular HMX, and have found fracture at very low pressures. Hardman et al. (3) also observed fracturing of other granular material at low pressures. Because of sample consolidation at high densities, however, many past studies have very little particle characterization of high density samples (4). In this section we present characterization of the 8 pressing densities considered, beginning with the original material.

\section{Unpressed HMX}

The original unpressed HMX (a typical particle is shown in Fig. 1) shows well formed crystal structures with 
identifiable facets, and few cracks or flaws. Particle size analysis at this density shows that the unpressed HMX has a mean particle diameter of $193 \mu \mathrm{m}$ (see Fig. 2). The largest volume percent of the sample is grouped around $178 \mu \mathrm{m}$ with a relatively low volume of small diameter particles. A fairly good comparison of this measured size distribution with a sieve analysis was achieved.

\section{Pressed HMX}

Figure 3 shows a typical HMX crystal after having been pressed to $70 \%$ TMD. Large cracks run throughout the structure of the crystal, however, the bulk of the original particle clings together. Particles at $80 \%$ TMD, see Fig. 4, are heavily damaged with increased evidence of fracturing and shearing. Finally, particles at $90 \%$ TMD, Fig. 5, are crushed to fine pieces which cling together in larger agglomerates of about $100 \mu \mathrm{m}$

As seen in Fig. 2, the mean particle diameter decreases with increasing density from $192 \mu \mathrm{m}$ to $131 \mu \mathrm{m}$ at $95 \%$ TMD. With increased pressures due to high-density pressing, many of the particles are cracked and sheared, leaving a much larger volume percent of particles in the $20 \mu \mathrm{m}$ to $40 \mu \mathrm{m}$ region. It does appear, however, that although highly fractured, (see Fig. 3) a large volume of the particles cling together, leaving the distributions of even the high density samples in the $100 \mu \mathrm{m}$ to $180 \mu \mathrm{m}$ range.

\section{$\underline{\text { Sonication Effects }}$}

One minute of sonication showed little effect on the mean particle diameter of the original HMX (Fig. 6). Because of the low power of the ultrasonic bath, and the unfractured state of the particles, the distribution was almost unchanged. (Compare "original" distributions from Fig. 2 and Fig. 6). As density increases, however, and the state of the particles becomes increasingly fractured, the effects of sonication become apparent. Distributions of samples from $65 \%$ and $70 \%$ TMD show increasing volumes of particles in the $<100$ $\mu \mathrm{m}$ range. At $75 \%$ TMD many of the large, but fractured particles are deconsolidated by the mild stimulus and we begin to see a transition to a bimodal distribution between 40 $\mu \mathrm{m}$ and $180 \mu \mathrm{m}$. This new $40 \mu \mathrm{m}$ mode becomes more prominent with increasing densities until the $180 \mu \mathrm{m}$ distribution completely disappears, and the remaining distribution tends toward $40 \mu \mathrm{m}$.

\section{BET Surface Area Analysis}

Increasing density due to pressing results in highly fractured particles with an increased surface area. Surface area per volume analysis, using the AUTOSORB-1, shows that surface area increases approximately linearly with density.

By assuming spherical particles, the size distributions obtained with the light scattering particle analyzer (Fig. 2) were converted to total surface area per unit volume, and plotted along with the AUTOSORB-1 data. Because of the mechanism used by the size analyzer, however, it is incapable of detecting fine cracks in fractured particles (see Figs. 3-5), thus underestimating the overall surface area. The data, however, display a linear increase with surface area as also seen in the AUTOSORB-1 data. A similar conversion using the size distributions from the sonication experiment (Fig. 6) is also plotted on the same axis. As seen, the deconsolidation of fractured particles by sonication shifts the conversion closer to the actual surface area analysis. It is also nearly linear with TMD, except at low TMD.

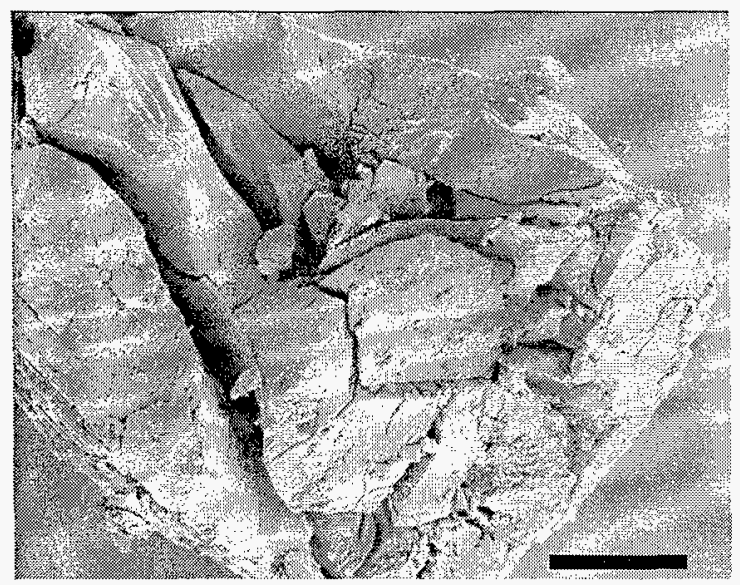

FIGURE 4. HMX $80 \%$ TMD (bar=10 $\mu \mathrm{m})$.

\section{DDT TUBE EXPERIMENTS}

Table 3 lists the DDT tube experiments performed and list the conditions considered. Figure $6 \mathrm{a}$ is a photo of a crosssectional view of the base case (shot \#1). There is a change from dark smooth walls to lighter walls, followed by darker pitted walls downstream. The color changes are visible in the photo, but are more identifiable visibly. Past analyses at LANL and elsewhere (see Luebcke, Dickson et al. 1996) have correlated the color changes to events in the transition process by comparing pin and slit-camera records with color changes on recovered walls. For example, the first dark to light change appeared to correspond to the intersection of a rearward traveling wave (driven by the detonation) and the initial burning wave in DDT experiments (Luebcke, Dickson et al. 1996). The second color change (light to dark) corresponded to the onset of detonation. Our analysis uses both color change and wall profile to define points that can be correlated to the DDT process (see Fig. 6b). Light intensity analysis with a reflective light microscope was used to accurately define the point of transition between light and dark regions, while digitized data from scanned images of the cross sections yield the wall profile. The wall profiles obtained have many of the same characteristics as previous thermally ignited tubes (Luebcke, Dickson et al. 1996). One distinguishing feature of these tubes is the widely expanded region followed by a region where the expansion decreases. This likely indicates that detonation occurred in the precompacted region, producing higher pressures, as well as, in the initial low density material. This scenario is consistent with highly diagnosed DDT experiments by (McAfee, Asay et al. 1991) who, under similar conditions, observe detonation beginning within the material compacted by the initial compaction wave. This indicates there are some qualitative 
differences between thermally ignited and piston-initiated experiments.

Closure pin data was obtained near the initial location of the piston in some of the experiments. This is shown in Fig. 7 for shots \#1 and \#2. There was a long ignition delay (about $400 \mathrm{~ms}$ compared with delays $<100 \mathrm{~ms}$ in the other experiments) due to tight packing of the titanium and boron in the ignitor block. This delay was probably accompanied by some burning in the chamber which pushed the piston into the bed slightly. Nevertheless, by shifting the initial time to correspond to the closure of the first pin in both shots \#1 and \#2 reasonable comparison between the two sets of pins is obtained. A wave speed of about $300 \mathrm{~m} / \mathrm{s}$ is observed which probably corresponds to the initial compaction wave. The ignition delay, and probable small movement of the piston from it's original position before full ignition appeared to shift identifiable points further downstream in the tube by 3-4 $\mathrm{mm}$ consistently. This is seen in Table 4 where the identified points are listed for the six experiments reported here.

Burn chamber pressure was also measured in some of the tests (see Fig. 8). The pressure rises quickly as the loose HMX burns in the chamber. The pressure attained in the high chamber load (shot \#4) is slightly more than a factor of two higher than the base case (shot \#1). The pressure is slightly higher in the $85 \%$ TMD case (shot \#6) than in the base case (shot \#1) due to the increased resistance to the movement of the piston by the higher density bed. Also shown in Fig. 8 is the time when detonation was indicated by a closure pin near the end of the tube.

An important objective of this work was to have a very repeatable experiment. Consequently, we repeated shot \#1 as closely as possible (shot \#3) and compared the results. We found that the two experiments were very close as indicated by the wall deformations reported (see Fig. 9) and other points of reference (see Table 3). These results are an indication that the experiments are fairly repeatable. Additional tests will hopefully verify this further.

Figures $10 \mathrm{a}, \mathrm{b}$ summarize the results obtained so far. Figure 10a shows the location of the first color change and Fig. 10b shows the second color change for the six cases. These color changes have been correlated to the transition event, as discussed above. It is clear that increasing the burn chamber pressure (piston speed) yields a much shorter run-todetonation, as expected. A slight decrease is observed at $75 \%$ TMD compared with $65 \%$ TMD, however, at $85 \%$ TMD there is a significant increase in the run-to-detonation. Although more data is needed to better define this curve, results appear qualitatively similar to those obtained by (Griffiths and Groocock 1960). Interestingly these results were obtained in piston-initiated DDT experiments that circumvent the initial convective burning mode. Convective burning issues have often been used to explain much of the Ushaped plot, however, convective burning is very likely irrelevant in these experiments. Increasing the density yields more rapid pressurization because more explosive is available in a given volume leading to a shorter run-to-detonation. There is a limit, however, after which further increases in density inhibits the formation of ignition sites. This type of effect has been explored to explain plug formation (Son, Asay et al. 1995).

\section{SUMMARY}

Initial results from a new series of experiments in heavily confined granular HMX were presented. These experiments were designed to be useful in model development and evaluation. The effect of density ( 3 densities so far), piston speed ( 2 speeds), and ignition delay on the DDT event have been considered. We have measured the particle size distribution of the original granular explosive and pressed (higher density) samples. Scanning electron microscope (SEM) pictures were presented for the materials used. These pictures were used to interpret the size distribution measurements and to more fully characterize the initial condition of the materials used. The size distribution changes significantly and the particles become increasingly fractured with pressing. Further, we found that sonication can significantly affect size distribution measurements. This effect becomes more apparent for the more fractured materials (higher pressed densities). For the base case (65\% TMD) two DDT experiments were performed yielding nearly identical results. This indicates that reproducibility was good. Run-todetonation, as indicated by color change and deformation of the on the inner wall, for the three densities $(65 \%, 75 \%$, and $85 \%$ TMD) considered show a slight decrease in run-todetonation going from $65 \%$ to $75 \%$ TMD and a significant increase at $85 \%$ TMD. Increasing the piston speed decreased the run-to-detonation. The effect of the ignition delay (tighter packing of titanium and boron) extended the run-todetonation.

Surface area analysis of class A HMX shows a nearly linear relationship between density and surface area per volume. Converted particle size analysis, however lacks the ability to account for fractures which leads to an under-prediction of the surface area. The increase of nearly an order of magnitude in the AUTOSORB-1 data corresponds to widespread fracturing and breaking of HMX particles by pressing. These results have significant implications on the modeling used to describe the burning and transition to detonation of granular HMX.

Several additional experiments are planned. The initial density will be varied over a broader range to better define the "U-shape" run-to-detonation plot. A few thermally ignited experiments, using the same tubes used here, will be performed to further examine the differences from pistonignited experiment. RDX is very similar to HMX, but burns very differently. For example, the "stand-off" distance of gas phase reactions in burning HMX is much larger than for RDX, at least at low pressures. To investigate this effect on the DDT event, RDX (with nearly the same size distribution) will be used in place of HMX also. As we press the granular HMX we are changing the density as well as the particle size distribution. To separate these two effects we plan to press to a higher density, deconsolidate the material and test the prepressed material at our standard low-density (65\% TMD). To better understand the effect of particle size on DDT, nearly monosized distributions of coarse and fine HMX particles will be tested. These experiments will use the same HMX as palnned for use in gas gun experiments. Also, to determine the significance of wall effects, similar tests will be run with 
tubes of larger i.d., while longer tubes may be implemented to confirm the development of a steady detonation wave. There remains some ambiguity concerning the interpretation of the pin and wall records. To clarify these issues we plan to use microwave interferometry to continuously measure piston velocity (at least part of it), compaction wave, and finally the detonation wave.

\section{ACKNOWLEDGMENTS}

The authors would like to acknowledge support for this work from Los Alamos National Laboratory which is supported by the U. S. Department of Energy under contract number W7405-ENG-36. The interest and support of Dr. Phil Howe is particularly appreciated. 


\section{REFERENCES}

Bernecker, R. R. (1986). "The Deflagration-to-Detonation Transition Process for High-Energy Propellants- A

Review." AIAA Journal 24(1): 82-91.

Bernecker, R. R. (1989). DDT Studies of a High Energy Spherical Ball Propellant. Ninth Symposium (International) on Detonation, Portland, OR.

Bernecker, R. R., H. W. Sandusky, et al. (1981). Deflagration-to-Detonation Transition Studies of Porous Charges in Plastic Tubes. Seventh Symposium (International) on Detonation, Annapolis, MD.

Bernecker, R. R., H. W. Sandusky, et al. (1985). Deflagration-to-Detonation Transition of a Double-Base Propellant. Eighth Symposium (International) on Detonation, Albuquerque, NM.

Griffiths, N. and J. M. Groocock (1960). "The Burning to Detonation of Solid Explosives." Journal Chemical Society of London 814: 4154-4162.

Korotkov, A. I., A. A. Sulimov, et al. (1969). "Transition from Combustion to Detonation in Porous Explosives." Fizika Goreniya i Vzryva 5(3): 315-325.

Luebcke, P. E., P. M. Dickson, et al. (1995). "An Experimental Study of the Deflagration-to-Detonation Transition in Granular Secondary Explosives." Proc. R. Soc. Lond. A 448: 439-448.

Luebcke, P. E., P. M. Dickson, et al. (1996). "Deflagration-to-Detonation Transistion in Granular Pentaerythritol Tetranitrate." J. Appl. Phys. 79(7): 3499-3503.

McAfee, J. M., B. W. Asay, et al. (1991). Deflagration to Detonation in Granular HMX. Proceedings of the Ninth International Detonation Symposium, Portland, Oregon.

Samirant, M. (1981). Deflagration to Detonation Transition in Waxed RDX. Seventh Symposium (International) on Detonation, Annapolis, MD.

Samirant, M. (1985). DDT in RDX and Ball Powder. Eighth Symposium (International) on Detonation, Albuquerque, NM.

Samirant, M. (1989). DDT-Determination of the Successive Phases of Phenomena. Ninth Symposium (International) on Detonation, Portland, OR.

Sandusky, H. W. (1983). Compressive Ignition and Burning in Porous Beds of Energetic Materials. 1983 JANNAF Propulsion Systems Hazards Subcommittee Meeting, Los Alamos, NM.

Son, S. F., B. W. Asay, et al. (1995). Reaction Rate Modeling in the Deflagration to Detonation Transistion of Granular Energetic Materials. MRS.

\section{REFERENCES}

1. Elban, W.L., Chiarito, M.A., Powder Technology 46, 181-193 (1986)

2. Coyne, Jr., Elban, W.L., Chiarito M.A., "The strain rate behavior of coarse HMX porous bed compaction," Presented at the Eighth Symposium (International) on Detonation, Albuquerque, NM, July 15-19, 1985

3. Hardman, J.S., Lilley, B.A., Proc. R. Soc. Lond 333, 183-199 (1973)

4. Butler, P.B., Haworth, M.E., Powder Technology 62, 171-181 (1990)

5. McAfee, J.M. et. al, "Deflagration to detonation in granular HMX," Presented at the Ninth Symposium (International) on Detonation, Portland, OR, Aug. 28-Sept. 1, 1989

6. Burnside N.J., Son S.F., Asay B.W, "Thick walled ddt tube experiments," Presented at the JANNAF PSHS Meeting, Naval Postgraduate School, Monterey, CA, Nov. 4-8, 1996

Skidmore, C.B., "Effects of Ultrasonic Bath Treatment on HMX Crystals," Los Alamos National Laboratory Unclassified Report LAUR-96-3522, 1996 


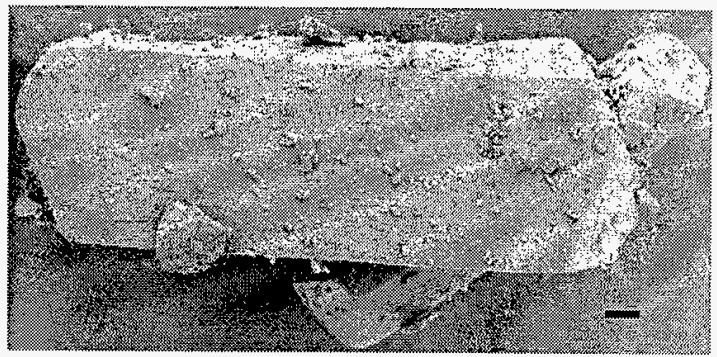

FIGURE 1. Unpressed HMX (bar=10 $\mu \mathrm{m})$.

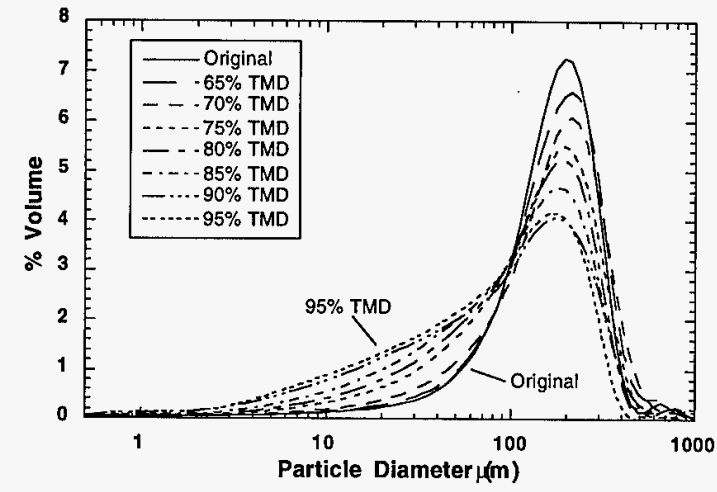

FIGURE 2. Particle size distributions of pressed HMX (No sonication).

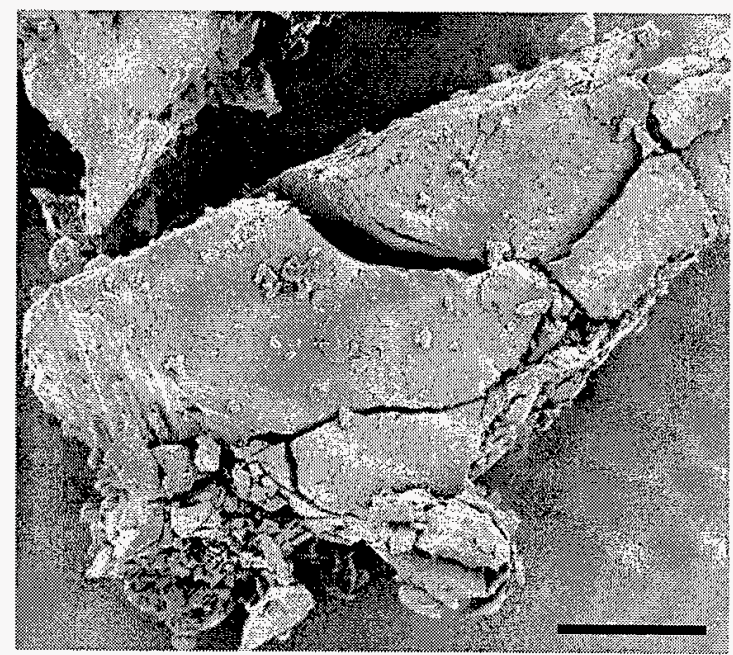

Figure 3. HMX 70\% TMD (bar=10 $\mu \mathrm{m})$ 


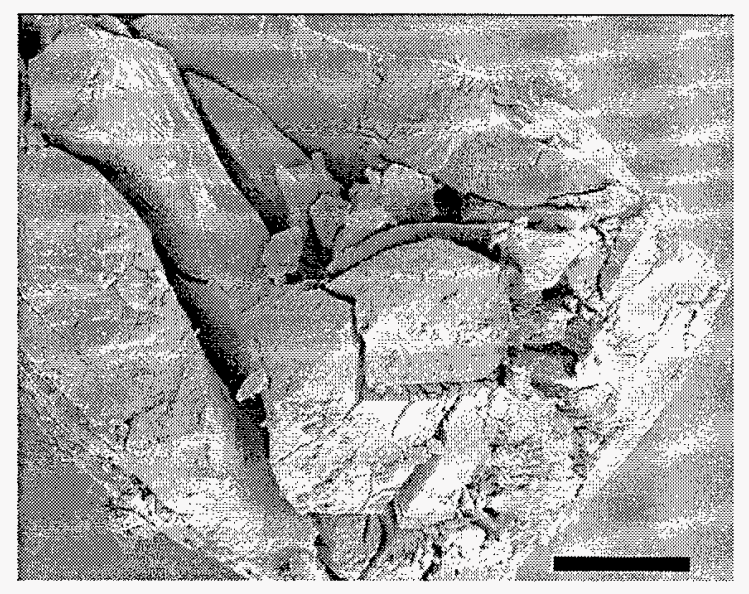

FIGURE 4. HMX $80 \%$ TMD (bar=10 $\mu \mathrm{m})$.

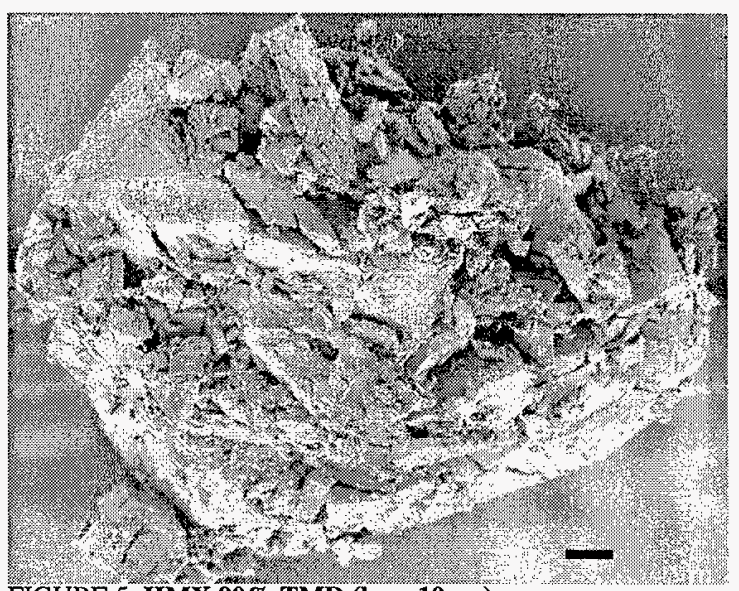

FIGURE 5. HMX $90 \%$ TMD (bar=10 $\mu \mathrm{m})$.

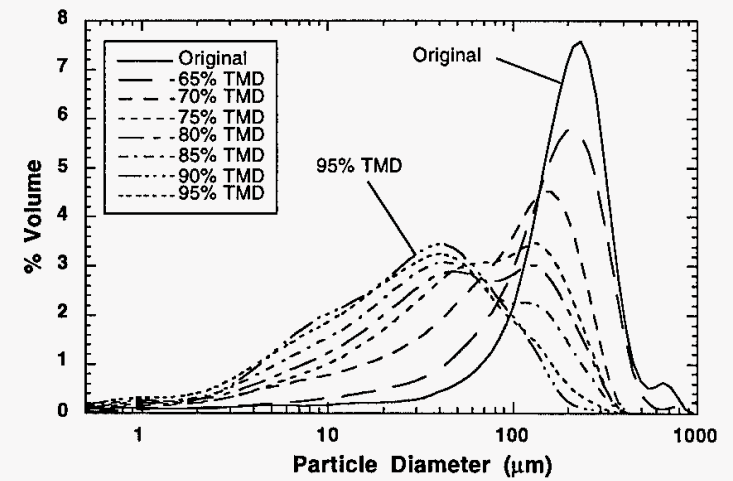

FIGURE 6. Particle size distributions of pressed HMX after one minute of sonication. 


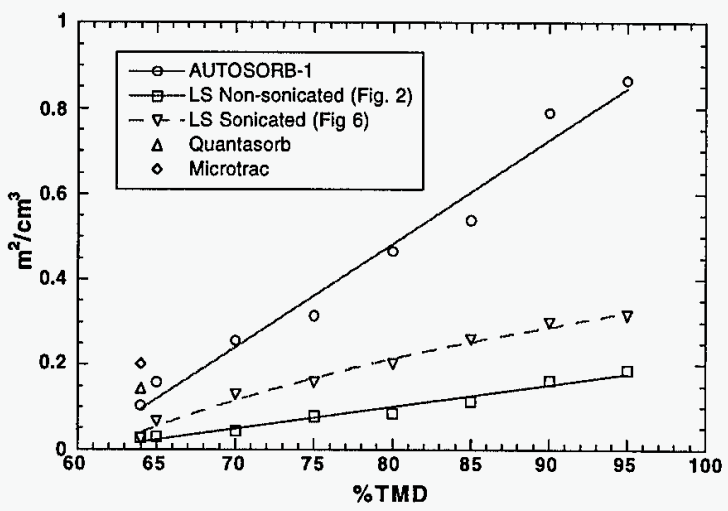

FIGURE 7. Surface area data taken with AUTOSORB-1 gas adsorbtion unit. Coulter LS data converted from particle size to surface area assuming spherical particles. Earlier data taken with Quantasorb and Microtrac systems.
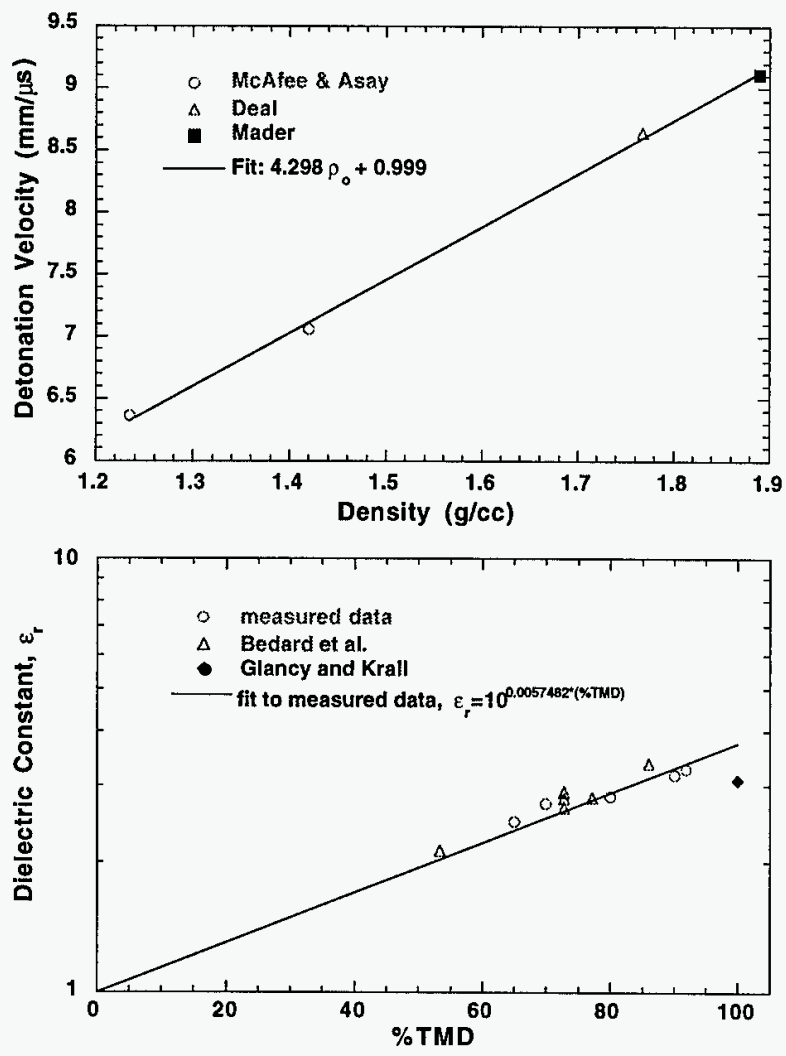

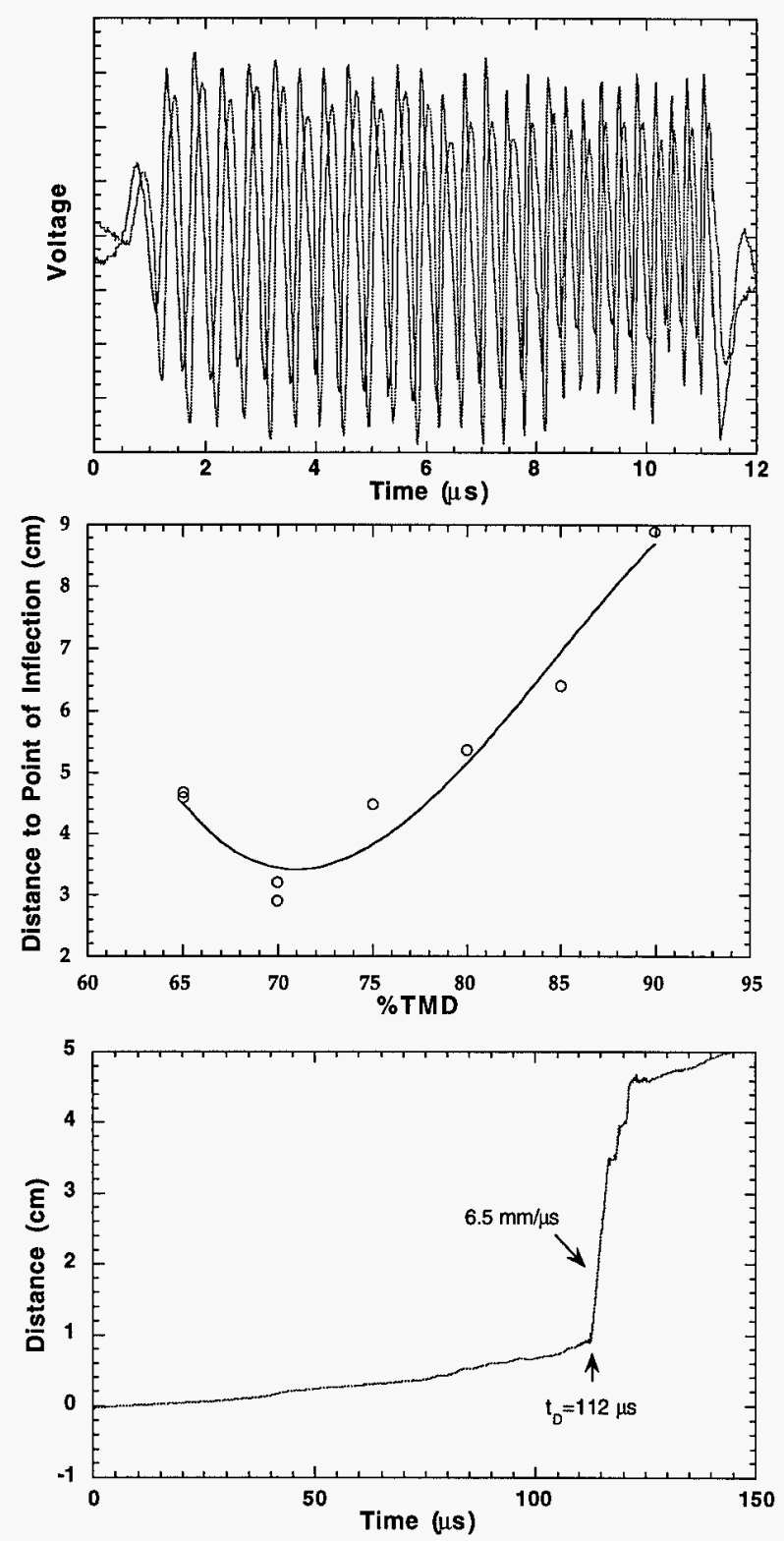


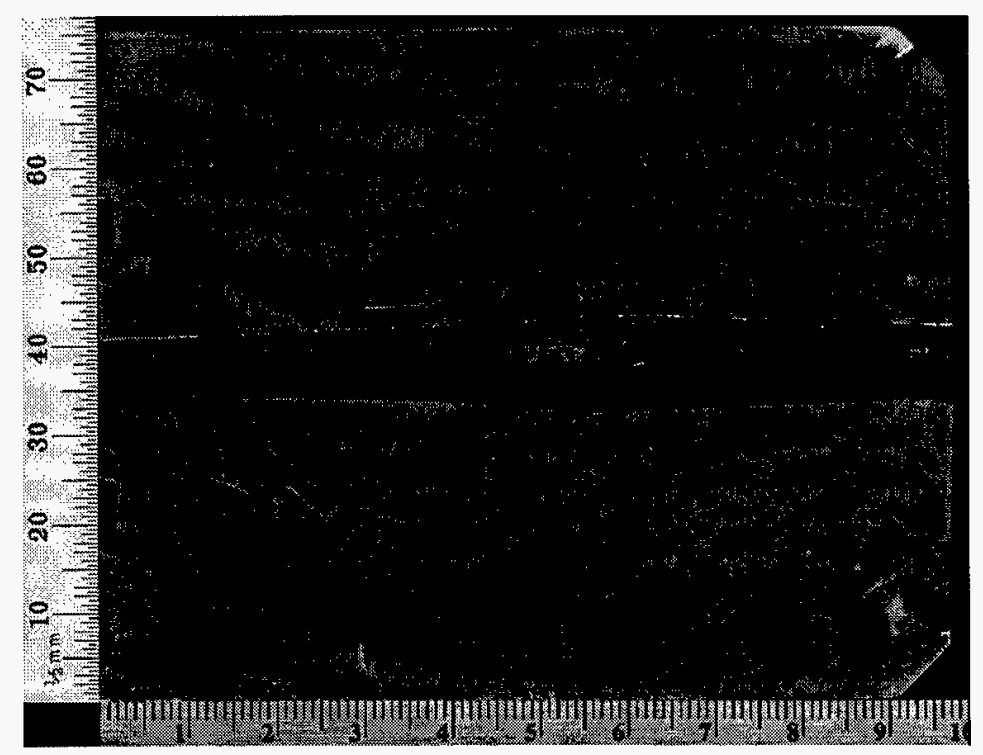


M98002943

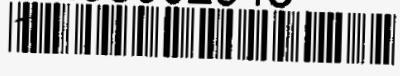

Report Number (14) $\frac{\angle A-U R-97-43 / 2}{\text { CONF-9710108-- }}$

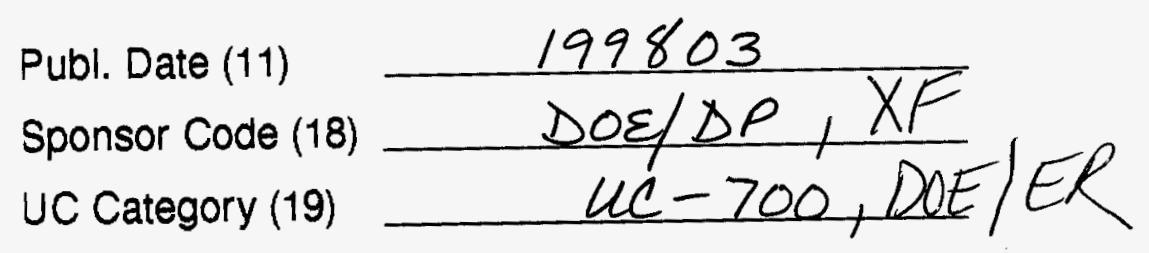

DOE 